\title{
Change in the Pattern of Paediatric Maxillofacial Fractures Seen In Kaduna, NORTHERN NIGERIA
}

Trauma is the leading cause of morbidity and mortality among children worldwide. ${ }^{1}$ However, in comparison with adults, maxillofacial fractures in children are relatively uncommon due to physiological and environmental factors. Between $4 \%$ and $12 \%$ of all maxillofacial fractures occur in children. ${ }^{2-5}$ The reasons for the wide disparity in incidence rates include differences in age limit of the pediatric population studied, types of injuries classified and the socio-economic status of the population which influences access to health care facilities.

Nigeria, like many developing countries in Africa has witnessed tremendous socio-economic and demographic changes in the past 20years. This has altered the pattern of some health conditions. Since the last published series on pediatric maxillofacial fractures from our center in $1980,{ }^{2}$ to our knowledge no recent review from our center has been presented. This is important as our center was the first oral/maxillofacial care center in northern Nigeria and remains an important tertiary care facility in the region. The aim of this report was to evaluate the current pattern of maxillofacial fractures in the urban Northern Nigerian pediatric population as seen at the Maxillofacial Unit, Ahmadu Bello University Teaching Hospital, Kaduna, Nigeria for comparison with other Nigerian and international records.

A retrospective survey of cases of maxillofacial fractures seen between 1991 and 2000 at the Maxillofacial Unit, Ahmadu Bello University Teaching Hospital, and Kaduna, Nigeria was undertaken. Children aged 15 years and below were selected out for further study. Materials reviewed include case notes, radiological reports and theater records. Information retrieved for analyses were age, sex, cause of fracture, site (s) of facial fracture, associated injuries and treatment. Poor return for follow-up made it impossible to review complications. Mandibular fractures were classified as anterior that is, between the canine teeth, posterior - from canine to end of occlusion, angle, ramus, condyle, dentoalveolar and coronoid types. Middle third fractures were classified as Le Fort type, Zygomatic complex and nasal complex types.

Out of 443 cases of maxillofacial fractures seen within the study period, 21 (4.7\%) were children aged
$15 y e a r s$ and below. There was a bimodal peak age of incidence at ages 9-10years old ( $n=7,33.3 \%$ ) and $13-15$ years old $(n=8,38 \%)$. The mean age of the children was $11.5 \pm 2.6 y e a r s$ (median age 11years) with no child below 6years of age. There were 15 males and 6 females. The main etiological factors were falls 12 , road crashes 6 , and fights 2 . A total of 29 maxillofacial fractures were seen in the 21 patients giving a fracture to patient ratio of 1.4:1. Five patients (24\%) had fractures of the middle-third and mandible but fractures most were mandibular only $(14,66 \%)$ while the rest were in the middle-third of the face alone (10). Treatment of cases is shown in Table 1. No associated injuries were recorded in the 21 children with maxillofacial fractures seen in this study.

Table 1. Treatment methods of maxillofacial fractures seen among Northern Nigerian children 15 y old and below

\begin{tabular}{ll}
\hline Treatment modality & No. \\
\hline Arch bar only & 11 \\
Eyelets and arc bar & 4 \\
Eyelets only & 3 \\
Arch bar + nasal POP & 1 \\
Arch bar + transosseous & 1 \\
wiring + frontomandibular suspension & \\
Gillies temporal approach & 1 \\
\hline Total & 21 \\
\hline
\end{tabular}

POP: Plaster of Paris

According to Nørholt et al., ${ }^{6}$ fractures of the pediatric maxillofacial skeleton are rare due to the resiliency of their bones, the relatively small size of their body in proportion to the head and the comparatively protected lifestyle of children. As they grow older, and get involved in more social activities, their incidence of fracture increases. Unlike in the 1980 report from our center, ${ }^{2}$ where 85 cases were seen in children aged 11 years old and below within 5 years, we saw 21 cases aged $15 y e a r s$ and below within 10years reflecting an apparent decrease in cases seen. Two reasons are postulated. 
As at 1980, our center was the only one managing maxillofacial fractures in the entire Northern Nigeria, hence the center "harvested" all the cases seen in the region while twenty years later several tertiary and secondary care facilities are in existence providing health care services to the population. Also, the economic downturn in Nigeria which started in the mid-1980's has decreased the level of car ownership of the Nigerian population. Previous Nigerian reports have shown that road crashes are responsible for most maxillofacial fracture cases. ${ }^{7-10}$

Generally, between $4 \%-12 \%$ of maxillofacial fracture occur in children. ${ }^{2-4}$ The incidence rate of $4.7 \%$ in this study is within the range of these earlier reports. The low incidence of facial fractures among children is due to physiological and environmental factors enumerated as; greater resilience of the pediatric skeleton, higher bone to tooth ratio direct parental supervision of the activities of young children and limited outdoor activity,. As they grow older, the incidence of facial fractures rises. ${ }^{6,11-15}$

Among Nigerian children, maxillofacial fractures occur twice as often in boys as in girls. ${ }^{2,3}$ In a report from lle-Ife, a semi-urban town in southwestern Nigeria, the male to female ratio was $3: 2$ possibly due to the predominance of road crash-related fractures in their environment. ${ }^{4}$ The present male to female ratio of 2.5:1 is similar to the earlier finding from our center. ${ }^{2}$ In the 1980 study, $15.3 \%$ of the children seen with facial fractures were 5 years old or below. ${ }^{2}$ The current study had no case in this age group. The bimodal peak seen in the earlier report (age 8-9years $23.5 \%$, age $12-13$ years $32.9 \%$ ) has shifted to age $9-12$ years (33.3\%) and age13-15years (35.2\%) in the present study. While the risk of fractures generally increases with age, ${ }^{1-4,16}$ it is speculated that the agerelated variations in injuries sustained are attributable to head-body relationship changes and development status of facial structures especially teeth and sinus. ${ }^{1,3,17}$

The main etiological factors in our report are falls (57\%) and road crashes (29\%) unlike in the 1980 report (falls $30.5 \%$, road crashes $54.1 \%$ ). This reversal reflects the decreased car ownership among Nigerians due to the economic downturn of the last 20 years. An etiological pattern similar to our current finding was also in the report from Enugu, another urban center in Eastern Nigeria, ${ }^{3}$ but unlike that from the semi-urban lle-Ife. ${ }^{4}$ The etiological pattern in Nigerian urban centers is similar to that found among Austrian children. ${ }^{5}$ This is unlike in the adult population were the etiological pattern in both the Nigerian urban and rural population are alike but dissimilar to that of Western Europe. ${ }^{2,9,10,18,19}$ A probable reason is that urbanization and changes in the lifestyle of Nigerian urban population is increasingly tending toward that of the European population hence parents may be more careful in supervising their children leading to reduction in rate of road crashes in children. Also, it is possible that severe cases of trauma do not make it to hospital.

Despite differences in etiological pattern between the pediatric and adult population, the jaw distribution of fractures is similar. More mandibular fractures are recorded in children than in the middlethird of the face. ${ }^{2-4}$ The reasons for this distribution have been previously reported. ${ }^{10}$ Adekeye $^{2}$ found that mandibular fractures were in the symphysis (24\%), body (21\%) and dentoalveolar (21\%) and condylar (12\%) regions. While symphyseal mandible is within our definition of anterior, more of our cases were in the anterior ( $n=7,30 \%$ of mandibular sites) with the rest as dentoalveolar ( $n=6,26 \%$ ) and posterior ( $26 \%$ of mandibular sites). This absence of condylar fractures in our study as compared to the 1980 report is surprising as they are more related to cases of fracture due to falls as the predominant etiological agent. ${ }^{17,20}$ However, while falls in our series were often in the home ie, associated with daily living, that in European studies are usually from bicycle and motorbikes resulting in greater impact on the chin.

Associated injuries with maxillofacial fractures could be life-threatening if not detected quickly and managed expertly. We found none in our review of 21 cases of maxillofacial fractures while Adekeye, ${ }^{2}$ had a $50 \%$ rate. While absence of associated injuries could be due to missed diagnosis; it is observed that high impact injuries such as road crashes and gunshot injuries are more associated with trauma to other body parts than falls., ${ }^{9,16}$

The methods of treatment of maxillofacial fractures in Nigerian children have been documented previously. $^{2-4}$ In our report, similar methods of treatment were utilized. While poor follow-up visits limit our ability to evaluate the implications of treatment on the growth of these children, we believe the results are satisfactory. Using mandibular fractures, Moreno et al., ${ }^{21}$ found that post-operative complications rates are fundamentally related to the severity of the fracture rather than to the treatment modality utilized.

\section{E. T. Adebayo ${ }^{1}$ and S. O. Ajike $^{2}$}

${ }^{1}$ Department of Dental Surgery, 44 Nigerian Army Reference Hospital, Kaduna, Nigeria.

E-mail: taiwo adebayo@yahoo.com

${ }^{2}$ Maxillofacial Unit, Ahmadu Bello University Teaching Hospital, Shika, Zaria, Nigeria

\section{References}

1. Haug RH, Foss J. Maxillofacial injuries in the paediatric patient. Oral Surg Oral Med Oral Pathol Oral Radiol Endod. 2000;90:126.

2. Adekeye EO. Paediatric fractures of the facial 
skeleton. A survey of 85 cases from Kaduna, Nigeria. Oral Surg. 1980;38:355-358.

3. Oji C. Fractures of the facial skeleton in children; a survey of patients under the age of 11years. J Cranio-Maxfac Surg. 1998;26:322-325.

4. Ugboko VI, Odusanya S, Ogunbodede E. Maxillofacial fractures in children. Paed Dent J. 1998;8:31-35.

5. Gassner R, Tuli T, Hachl O, Moreira R, Ulmer H. Cranio maxillofacial trauma in children: a review of 3385 cases with 6060 injuries in 10years. J Oral Maxillofac Surg. 2004;62:399-407.

6. Norholt SE, Khrishnan V, Sidet-Pedersen S, Jensen IB. Paediatric condylar fractures: a longterm follow-up study of 55 patients. J Oral Maxillofac Surg. 1993;41:1302-1310.

7. Odusanya SA. Maxillofacial fractures in Southwestern Nigeria (1997-1981). Trop Dent J. 1985;3:153-156.

8. Abiose BO. Maxillofacial skeleton injuries in the Western states of Nigeria. Br J Oral Maxillofac Surg. 1986;24:31-39.

9. Ugboko VI, Odusanya SA, Fagade OO. Maxillofacial fractures in a semi-urban Nigerian teaching hospital. A review of 442 cases. Int J Oral Maxillofac Surg. 1998;27:286-289.

10. Adebayo ET, Ajike SO, Adekeye EO. Analysis of the pattern of maxillofacial fractures in Kaduna, Nigeria. Br J Oral Maxillofac Surg. 2003;4:396400.

11. Maclennan WD. Injuries involving the teeth and jaw in young children. Arch Dis Child. 1957;32:492.
12. Kazanjian VH, Converse JM. The surgical treatment of facial fractures. 2nd edn. Williams and Wilkins Co., Baltimore 1959, pg 306.

13. Hagan EH, Huelke DF. An analysis of 319 case reports of mandibular fractures. J Oral Surg. 1961;19:93-104.

14. Rowe NL, Killey HC. Fractures of the facial skeleton. Churchill Livingstone, London 1968. pg 173-9.

15. Al-Aboosi K, Perriman A. One hundred cases of mandibular fractures in Iraq. Int J Oral Surg. 1976;5:8-12.

16. Bamjee $Y$, Lownie JF, Cleaton-Jones PE, Lownie MA. Maxillofacial injuries in a group of South Africans under 18years of age. Br J Oral Maxillofac Surg. 1996;34:298-302.

17. Posnick JC, Wells M, Pron GE. Paediatric facial fractures in children: evolving patterns of treatment. J Oral Maxillofac Surg. 1993;51:836844.

18. Choung R, Donoff RB, Guralnick WC. A retrospective analysis of 327 mandibular fractures. J Oral Maxillofac Surg. 1983;41:305309.

19. Brown RD, Cowpe JG. Patterns of maxillofacial trauma in two different countries. A comparison between Riyadh and Tayside. J R Coll Surg Edinb. 1985;30:299-302.

20. Kaban LB, Mulliken JB, Murray JE. Facial fractures in children. Plast Reconstr Surg. 1977;59:15-20.

21. Moreno JC, Fernandez A, Ortiz JA, Montalvo JJ. Complication rates associated with different treatment for mandibular fractures. J Oral Maxillofac Surg. 2000;58:273-280. discussion 280-1.

\section{Spontaneous Vaginal Delivery of Undiagnosed BIPAgOUS CONJOINT TWINS}

Conjoint twins are usually rare events. The incidence in our environment has not really been documented but there have been previous reports. ${ }^{1,2}$ Conjoint twins are classified in different ways. If they are fully formed except for the parts of con-junction, they are called bipagous conjoint twins (or duplicata completa).

Vaginal delivery of conjoint twins was documented in $1950^{3}$ and $1981^{4}$ in Western countries. None, to our knowledge, has been reported in Nigeria. We report a case of undiagnosed bipagous conjoint twins that were delivered by Spontaneous vaginal delivery, unassisted and in a primary level health facility.

A 29-year old woman on the 18th of September 2004 with history of delivery of a set of conjoint twins at a Rural Health Centre.
She was gravida 4 para 3 with 2 living children. Though she registered for antenatal care in a private hospital, she did not carry out any investigation including ultrasound or plain x-rays. She had nothing suggestive of "big -for-date" pregnancy or polyhydramnios during the pregnancy. At about 39 weeks, she went into spontaneous labor and was rushed to the nearest rural health center where she was assisted by the attendant midwife to have a spontaneous vaginal delivery of a set of conjoint twins. Both twins cried immediately after birth, passed meconium from their respective ani and also passed urine normally. They were promptly referred to our Teaching Hospital.

At presentation the babies were about four hours old, cold to touch and wrapped in their mother's delivery cloths. Both were females with a 